\title{
District Partisan Homogeneity, Communications, and the Electoral Motive: An Analysis of the Facebook Posts of Members of the U.S. House of Representatives
}

\author{
Scot Schraufnagel'1, Quan Li², Adam Schuster ${ }^{3}$ \\ ${ }^{1}$ Department of Political Science, Northern Illinois University, DeKalb, Illinois, USA \\ ${ }^{2}$ College of Political Science and Public Administration, Wuhan University, Wuhan, China \\ ${ }^{3}$ Northern Illinois University, DeKalb, Illinois, USA \\ Email: sschrauf@niu.edu, quanli3387@163.com
}

How to cite this paper: Schraufnagel, S., Li, Q. and Schuster, A. (2017) District Partisan Homogeneity, Communications, and the Electoral Motive: An Analysis of the Facebook Posts of Members of the U.S. House of Representatives. Social Networking, 6, 148-163.

https://doi.org/10.4236/sn.2017.62009

Received: November 16, 2016

Accepted: April 25, 2017

Published: April 28, 2017

Copyright (c) 2017 by authors and Scientific Research Publishing Inc. This work is licensed under the Creative Commons Attribution International License (CC BY 4.0).

http://creativecommons.org/licenses/by/4.0/

\begin{abstract}
The research examines the way in which members of the U.S. House of Representative represent themselves on the social network site Facebook. Each member's activity is observed on seven different occasions and the frequency and substantive character of posts made during the second half of 2013 are established. The focus is on position-taking posts versus posts which mention the district the member serves in. Our expectation is that members from electorally safe districts will be more likely to advertise their policy positions while members from marginal districts will be more inclined to advertise their district connections. We control for minority party status, gender, and ideological extremism among other concerns and learn electoral safety is a good predictor of both "position-taking" and "district mentions". Consistent with an electoral motive, we also find members from the minority party less likely to take positions on the issues of the day and more likely to mention the district they serve in.
\end{abstract}

\section{Keywords}

U.S. House of Representatives, Facebook Posts, Electoral Motives, Credit Claiming

\section{Introduction}

What follows is an analysis of House members' Facebook communication style under different electoral conditions. Our primary intention is to test whether members who run in electorally safe districts are more likely to take positions on the issues of the day, and correspondingly, whether electoral insecure members 
are more likely to use Facebook to advertise their connections to the district they serve in. Grimmer [1] and Grimmer et al. [2] find senators and House members in tighter electoral contests do more "credit claiming," and that electorally safe members are more inclined to take positions on issues, in the member's press releases. This research can be deemed, in part, a replication of Grimmer's work ([1]), but our analysis is of a different mode of messaging and our focus is more directly on electoral circumstances as opposed to the dynamics of credit claiming communication.

Beyond our investigation of electoral situations, we do investigate other possible correlates with the subject matter of Facebook posts. In particular, we are interested to test whether members of the minority party are more or less inclined to take positions on the issues of the day. Consistent with electoral aims, our hunch is that members of the minority will deemphasize policy and as a substitute, advertise their district connections. In other words, members of the minority party might be more cautious in their public pronouncements as they strategize retaking the chamber. Furthermore, we look to test whether bill sponsorship and party leadership affect the type of Facebook posts members make, while controlling for tenure, ideological extremism, gender, age, and district demographics. A healthy legislative process might find leaders and bill sponsors taking "the lead," discussing openly, and rallying support for policy positions they deem in the best interest of the country.

In the end, most of our suspicions are confirmed. In particular, we find members running in less competitive districts are more likely to take the liberty of advertising their issue positions. Unfortunately, the advertising is not always matterof-fact and sometimes is acerbic and can be seen to fuel partisan conflict by stoking co-partisan ire toward those holding opposing views. On the other hand, members in marginal districts, holding party constant, are more likely to discuss their district connections in Facebook posts, with implications for the delegate model of representation. The paper proceeds to provide details regarding data collection and the measurement of relevant concepts. This is followed by a discussion of model specification, our findings, and an argument about the possible implications of our findings for the quality of political discourse in the United States.

\section{The Scholarly Opening for this Inquiry}

Fenno's ([3]) work on the "home style" of House members must be viewed as foundational to this study. Fenno argued that constituents will demand substance and that they need their member to justify votes and the policies they pursue. Moreover, he notes that "explaining" policy positions is done to gain constituent support, but can also serve an "education" function ([3], 162). The contemporary work of Grimmer ([1]) uses the press releases of senators to test who in the Upper Chamber is more likely to take positions on issues versus claim credit for legislative accomplishments. We follow the lead of both Fenno and Grimmer (see also [4]), and code Facebook posts for "position-taking".

Scholars also suggest members taking credit for spending in a state or district, 
whether the spending actually occurs or not, has important implications for representational style ([1] [2]). The inferences are that credit-claiming activity is done more when members are less electorally secure and that it draws tighter the depictive association between members of Congress and their constituents. Fenno, for his part, argues for reporters and academics to focus on "constituency-centered research" or member districts ([3], 21). We combine the insights of Grimmer and Fenno and track "district mentions," coding each Facebook post " 1 " if it in anyway advertises a member's district connections. ${ }^{1}$

Beyond the broader value of studying position-taking and district connections this work follows in the footsteps of Mayhew ([5]) who was interested in uncovering the behavior of members motivated by different electoral conditions (Chapter 1). Carson and Jenkins ([6]) have shown that the electoral prospects of members have been influencing legislative behavior since the very early years of the republic and that part of the "connection" relates to a legislator's willingness to publically take positions on the issues of the day. Still others note the perceived level of electoral competition has implications for strategic retirement ([7]) and strategic candidate entry ([8]). Moreover, and consistent with those who argue that the ideological heterogeneity of constituencies has implications for governance ([9] [10]), and others who study attention paid to the district overtime and under different circumstances ([11], Chapter 8; [12]), this work seeks to test the effect district partisan homogeneity, and the status as a member of the minority party, have on member/public exchanges, using a wholly $21^{\text {st }}$ century communications medium. ${ }^{2}$

\section{Data Collection}

Most of our data collection decisions are informed by previous efforts to record member social media use. Specifically, [4] [13]'s work is consulted. Initially, these authors conduct a study of Twitter use by members of the $111^{\text {th }}$ Congress

${ }^{1}$ We deviate from ([1]), who emphasized "credit claiming," because our interests are primarily in electoral politics and testing the strategies of members who find themselves operating under different electoral conditions. For instance, if a member posts congratulatory remarks aimed at a high school sports team in their district we hold this has electoral implications and count this post in our category "district mentions". The member may be trying to ingratiate herself to locals and broaden their re-election constituency ([3], p. 8). But, the member is also forced to consider their district connections, which can lead to a more proactive delegate style of representation. A measure which only captured credit claiming would not necessarily pick this up.

${ }^{2}$ Facebook was founded on February $4^{\text {th }}, 2004$.

${ }^{3}[4]$ repeat their study in the $112^{\text {th }}$ Congress, adding Facebook to the data collection procedures and collect posts for a two month rather than two week period and find that position-taking had, in a very short amount of time, become the most common type of post. The change may occur in part because of a guide released by Facebook in 2012 on how representatives should use site. The guide suggests position-taking and explaining votes was one of the best ways to use the medium; James Johnson. 2012. "Facebook Creates Guide For Members of Congress, Explains Pages." The Blog Herald:

http://www.blogherald.com/2012/11/30/facebook-creates-guide-for-members-of-congress-explainspages/ (last accessed June 29, 2015).

${ }^{4}$ Another study by the Center for Politics and Governance ([14]) collected messages posted on Facebook, Twitter, and YouTube and also found Republicans more likely to adopt social media and more likely to post often. 
over a two-week period in the fall of 2009. ${ }^{3}$ They find Republicans were more likely to be on Twitter and more likely to Tweet often; ${ }^{4}$ that members posted more during a recess, and that members Tweet more during the middle of the week and less on weekends. Based on their research we also account for the partisanship of members, recesses, and the day of the week a post is made in our original data collection effort. We consider the question of partisanship particularly interesting. However, we imagine a more compelling query, particularly as it relates to elections, is majority versus minority party status. We suspect standing as a member of the minority party, and not the actual party label, will influence the tenor of public communications. The timing of posts at first blush might seem less interesting; however, we might imagine during a recess, when a member is more likely to be staying in the district, that posts about the district will be more prevalent and, hence, this becomes an important control variable for our analysis. The same can be said about weekend versus weekday posts. One might suppose more posts about the district on the weekend when members are more likely back home.

Taken together, previous efforts to categorize social media activity provide a useful starting point, but leave many questions unanswered, particularly as it relates to the style of communication under different levels of electoral security. Hence, we embark on an original study and collect data on all House members serving in the $113^{\text {th }}$ Congress from Tuesday, June $18^{\text {th }}$ to Monday, December $9^{\text {th }}$, 2013. ${ }^{5}$ All members are considered because each had an official Facebook page. Each member's home page was observed seven times, once on each day of the week, over a roughly six month period of time. Thirty-seven members (8.5 percent) made no posts on any of the seven days their Facebook page was observed. The six-month period is longer than previous studies of social media practice by members of Congress, which arguably creates an opportunity to better capture "typical" use, as opposed to idiosyncratic time-specific use of Facebook. We also purposefully collect data in a non-election year as a way of measuring member communications unconstrained by a heated election campaign.

We focus, in this paper, on two dependent variables or measures of the substantive quality of member posts. The first we label "position-taking" and this indicates whether a Facebook post mentions a public policy issue with the member offering either support or opposition. A couple of typical posts from this category include:

\footnotetext{
${ }^{5}$ We use roughly the same coding categories as [4] [13] and [14] but add additional categories in order to remove their "other" designation. Our categories are position-taking, policy (without position-taking), district mention, an official act of Congress, tragedy, media events, national celebrations (July $4^{\text {th }}$; Labor Day; Halloween, etc.), and personnel matters. Other's coding scheme includes a "campaign" category, but because the present study did not take place in a campaign year and we did not have campaign related posts this consideration was dropped. Consistent with the Congressional Research Service studies we make no distinction between the different types of Facebook pages employed and no attempt is made to determine who is actually posting. In some cases, it is clear that the member is not the one posting in other instances it is difficult to know for sure. Consistent with work on press releases and other forms of public pronouncements we assume the Facebook post represents members' views.
} 
Representative Billy Long (R-MO): "I strongly believe in protecting the American people's Fourth Amendment rights and privacy rights from government intrusion. The key word here is American. The Nugent Amendment I voted for stops the collection, storage, or monitoring of electronic communications of a United States citizen."

and

Candice Miller (R-MI): “This week the House of Representative will vote on legislation that I am proud to cosponsor, H.R. 2009. This bill would bar the IRS from implementing or enforcing any component of President Obama's health care law and end the requirement that Americans must share with the IRS much of their most personal and private health care information."

The second dependent variable examines whether a post mentions the member's district or raises specific district and/or local issues. In one instance a constituent asked her representative, via Facebook, for more pocket Constitutions to distribute to local high school students. Representative Allyson Schwartz (D-NY) replied:

"Hi Jules, please give our District Director, Michelle Espinal a call at 215335-3355 and she would be happy to assist you."

In another instance, a member warns his constituents about high temperatures:

Representative Jim Himes (D-CT): "With temperatures reaching into the 90 s today, overheating can become a serious danger. Please check on elderly family and neighbors and remember not to leave pets in cars unattended. Here are some local places to stay cool: ...”.

On average, the difference between position-taking posts and district mentions is stark and very easy to code. However, there were some instances where it was difficult to disentangle the primacy of the two considerations. Of the 4159 observations we code 1067 as position-taking and 674 as district related. In 98 instances the member post made a clear reference to the district, while also mentioning the legislator's position on a legislative topic. These posts are scored "1" under both indicators.

Our key explanatory variable is district partisan homogeneity. We measure the concept using the logic of the Partisan Voting Index (PVI) developed by Charlie Cook. The PVI compares the average Democratic Party presidential vote in the two preceding elections to the average district Democratic Party presidential vote in those same elections. We use the absolute value of the PVI as our predictor. The variable ranges from "0" which means the district voted for the Democratic Party presidential candidate at the same rate as the nation as a whole. At the other extreme the variable takes on the value of " 43 " in New York's District 15. In 2013, José E. Serrano D-NY was the incumbent. Correspondingly, the most "homogeneous" Republican district takes on a value of 32. This is Mac Thornberry's $13^{\text {th }}$ district in Texas, a seat he has held since 1995. The score of 32 indicates the district supports the Democratic Party presidential candidate at a 
much lower rate than the nation as a whole. The logic we are employing suggests New York's $15^{\text {th }}$ and the Texas' $13^{\text {th }}$ are safe districts for Democrats and Republicans, respectively, and we expect more opportunity for position-taking and less pressure to discuss one's district connections. ${ }^{6}$

As alluded to we also collect data on other considerations. Importantly, we score each post " 1 " if the member is from the minority party in the House and we expect less position-taking and more mentions of the district. This insight is supported by research which suggests majority versus minority party status is an important predictor of legislative behavior ([15]) and that majority party status has implications for the effect party polarization and other considerations have on the electoral security of members ([16]). In the end, because this analysis is limited to a single Congress we will not know definitively whether it is the Democratic Party label or minority party status that is responsible for our findings. Yet, we feel confident that theory and previous research supports our contentions that a majority/minority party position influences legislative behavior ([17]) as much as the actual party label.

Next, we measure bill sponsorship activity. Specifically, the number of bills sponsored or co-sponsored during the time period of the study is counted. The variable ranges from 0 to 27 with a mean of 2.94. Our expectation is that the number of bills sponsored will associate positively with position-taking. Members sponsoring legislation might be more likely to want to advertise their position on a particular issue as they attempt to rally public support for their legislative initiatives. We do not expect this consideration to have a substantively interesting, or statistical relationship, to "district mentions." Correspondingly, we include two leadership considerations. Scholarship suggests the study of congressional leaders is important ([18] [19] [20]) and the contention that contemporary leaders have increasingly become agents of their political parties ([21]) suggests increased responsibility to advertise the party's legislative agenda. First, we score posts "1" for "party leaders," and second, "1" if the member being observed is the chair or ranking member of one of the House standing committees.

Our consideration of leadership and their role as party spokespersons may, however, be conditioned by tenure. Newly minted committee chairs or ranking members may not have the gravitas, or electoral security, to feel comfortable advocating for specific policy positions. We imagine it is longer serving leaders who will be most inclined to play the role of party voice or party policy entrepreneur. Hence, we are particularly interested in the interaction between tenure and leadership. Tenure, alone, we suspect will be negatively related to substantive posting. The average tenure of the 37 members who made no posts was nearly 18 years and these member observations represent many zeros in our

${ }^{6}$ As an alternative model specification we employ each member's 2012 election vote total and obtain results substantively and statistically consistent with the measure of district partisan homogeneity used in the models displayed.

${ }^{7} \mathrm{We}$ consider party leaders to include the speaker, majority leader, minority leader, majority whip, minority whip, Democratic caucus chair, Republican conference chair, and the party Policy Committee chairs. 
coding scheme ( $37 \times 7$ or 259$)$. Moreover, previous work finds that more senior members of Congress sending out fewer constituent messages in the form of direct mail ([22]). To reiterate, we hypothesis a negative relationship for tenure and both types of posts, but that the interaction between tenure and the two leadership considerations will return statistically significant positive associations.

Next, we control for ideological extremism, which we hold will lead a member to be more outspoken and more likely to make position-taking posts on Facebook. As an aside, we know ideological extremism can be a function of district partisan homogeneity ([23]), hence, the inclusion of this variable will ensure a robust test of our primary thesis regarding electoral security (or the partisan homogeneity of the district). We use the absolute value of the difference between each member's personal DW-NOMINATE score and the chamber median DW-NOMINATE score in the $113^{\text {th }}$ Congress. Higher values indicate more extreme voting behavior and we are expecting a positive association with position-taking but no statistical or substantive relationship with district mentions.

We also explore gender and age, scoring cases " 1 " if the member is female, and filling in the member age at the time the post was made. ${ }^{8}$ A priori we do not have any strong expectation for the gender or age considerations, but are curious to learn whether female legislators may be different from their male counterparts in their Facebook communications. We also include measures of district median income and the percent college graduates in each House district. Grimmer et al. ([2], 23), cite others, and argue members might be more predisposed to claim credit for government spending in the district if constituents, on average, are lower income because lower income citizens will better appreciate government spending. They also argue, more college graduates in the district will make members less likely to claim credit for spending and more likely to take positions on issues in their press releases. Consistent with their insights, we hypothesize that members will make more district mentions in lower income districts and do less position-taking in these same districts. More college graduates in the district should produce more position-taking posts and be inversely related to district mentions. Last we control for legislative recesses and the day of the week.

\section{Model Specifications}

Much of our discussion to this point suggests that each member might be the appropriate unit of analysis. By looking at only a single Congress, for instance, we have only one value for the percent of college graduates in the district and the district's medium income. Although we do allow member age and tenure to change over the six-month data collection period, there is not much in the way of variation with these variables either. Hence, we begin by using each member's average age and tenure and drop the consideration of recesses and the day of the week and create two dependent variables representing the proportion of posts

${ }^{8}$ With both the tenure and age variables we calculate the number of days from when the member was either sworn-in or born and the date the member's Facebook activity was observed. We divide the number of days by 365.25 to obtain a yearly value. 
each member makes that are position-taking and the proportion of posts each member makes that mention the district they serve in. Since these dependent variables range between 0 and 1, using ordinary regression is problematic. Instead, we use a generalized linear model with a logit link and the binomial family. In addition, we included robust standard errors to control for any potential model misspecification ([24]). Because 37 member offices did not make a post on any of the seven observation days they are dropped from this first analysis.

To check the stoutness of our findings and to control for recesses and the day of the week in a manner similar to the earliest works on social media use by members of Congress ([4]), ${ }^{9}$ we also test the substance of Facebook posts using each member observation as the unit of analysis. This tactic produces dichotomous dependent variables, scored " 1 " if when a member's page was observed there was either a position-taking or a district post and "0" if there was not. Because 437 different members' Facebook activity was observed seven times during the six-month window, the minimum sample size is $3059(437 \times 7)$. However, 155 House members, sometimes, posted more than once per day and we count each post, on the day they were observed, as part of our sample. This causes the sample size to grow to $4159 .{ }^{10}$ Now, we use logit regression with the VCE option. The VCE option in logit specifies how to estimate the variance-covariance matrix corresponding to the parameters. The standard errors reported in the output are the square root of the diagonal elements of the variance-covariance matrix. Specifically, we use the VCE option and cluster the errors by a member marker, which specifies that the standard errors allow for intragroup correlation, relaxing the requirement that the observations be independent, but controlling for any with-in group correlation. ${ }^{11}$ The residuals of our models are checked against the independent variables and do not indicate any heteroskedasticity.

\section{Findings}

Turning to Table 1, which reports regression results when the dependent variable is the proportion of district or position-taking posts, the testing has returned statistically significant findings, regarding electoral conditions, in three out of four tests. District partisan homogeneity or electoral safety does not influence position-taking posts positively as hypothesized. However, in the more homo-

\footnotetext{
${ }^{9}$ Findings regarding the day of the week are not presented in the tables that follow. We leave out Sunday and learn that members always make more position-taking posts on other days of the week. In addition, members make more district posts on weekends, but there is no difference between Saturday and Sunday in the probability of a district mention.

${ }^{10}$ The modal number of posts per day is " 1 " and the mean number of posts per day was 1.21 . Kevin Brady (R-TX) did the maximum amount of posting, averaging over eight posts per day during the seven observation periods.

${ }^{11}$ Initially we suspected that representatives' posting behavior consists of two related stages. At the first stage, they determine whether to make a post, followed by a second stage decision whether or not to make a substantive policy post. Nevertheless, the Wald test from our two-stage selection models indicates that the two stages are independent of each other. The decision to make a post does not influence the decision to make a substantive policy post. In order to focus on the electoral implications of representatives' postings, we decided to focus on the second stage and examine only the factors that influence the decision to make position-taking or district posts.
} 
Table 1. Explaining the Substance of Member Facebook Posts: $113^{\text {th }}$ Congress. Generalized Linear Model: Proportion of Each Members' Facebook Posts on a Subject using a Logit Link.

\begin{tabular}{|c|c|c|c|c|}
\hline \multirow[b]{2}{*}{ Independent Variables } & \multicolumn{2}{|c|}{ Position-Taking Posts } & \multicolumn{2}{|c|}{ District Mention Posts } \\
\hline & Expectation & Coef. (s.e.) & Expectation & Coef. (s.e.) \\
\hline District Partisan Homogeneity & Positive & $0.006(0.008)$ & Negative & $-0.033(0.009)^{*}$ \\
\hline Minority Party Member & Negative & $-0.540(0.211)^{\star}$ & Positive & $0.512(0.229)^{*}$ \\
\hline Bills Sponsored (count) & Positive & $-0.018(0.020)$ & Null & $-0.016(0.025)$ \\
\hline Member Tenure & Negative & $0.014(0.010)^{\wedge}$ & Negative & $0.003(0.011)$ \\
\hline Party Leaders & Undefined $^{\mathrm{a}}$ & $-1.15(0.625)$ & Undefined & $-0.381(1.29)$ \\
\hline Tenure $\mathrm{x}$ Party Leader & Positive & $2.0^{\mathrm{e}-4}\left(8.6^{\mathrm{e}-5}\right)^{\star}$ & Negative & $-0.0000(0.0001)$ \\
\hline Chairs/Ranking Members & Undefined & $-0.081(0.511)$ & Undefined & $-0.624(0.583)$ \\
\hline Tenure $\times$ Chairs/Ranking & Positive & $0.004(0.023)$ & Negative & $-0.001(0.026)$ \\
\hline Ideologue & Positive & $0.503(0.357)^{\mathrm{t}}$ & Null & $-0.346(0.408)$ \\
\hline Female & Null & $0.315(0.146)^{*}$ & Null & $0.005(0.181)$ \\
\hline Member Age & Null & $-0.005(0.007)$ & Null & $-0.002(0.007)$ \\
\hline Med. Dist. Income (10,000’s \$) & Positive & $0.005(0.012)$ & Negative & $-0.007(0.014)$ \\
\hline \% District College Educated & Positive & $0.003(0.003)$ & Negative & $0.004(0.007)$ \\
\hline Constant & \multicolumn{2}{|c|}{$-0.231(0.391)$} & \multicolumn{2}{|c|}{$-0.346(0.449)$} \\
\hline AIC & \multicolumn{2}{|c|}{1.124} & \multicolumn{2}{|r|}{0.949} \\
\hline BIC & \multicolumn{2}{|c|}{-2134.086} & \multicolumn{2}{|c|}{-2158.713} \\
\hline n-members & \multicolumn{2}{|r|}{400} & \multicolumn{2}{|r|}{400} \\
\hline
\end{tabular}

${ }^{\mathrm{t}} p<0.10 ;{ }^{\star} p<0.05 ; \wedge$ statistically significant in the wrong direction (one-tailed tests). ${ }^{\text {a }}$ Some expectations are "undefined" because they do not represent real-world conditions. Because of the specified interaction between party leaders and member tenure the coefficient for "Party Leaders" represents the probability of a party leader with no tenure making a position-taking post. Party leaders with no tenure do not exist.

geneous districts there is a decrease in district mentions. We learn that a one standard deviation increase in district partisan homogeneity (roughly an eight percent change) decreases the proportion of district mentions by a factor of 0.75 . In our data, the average percentage of posts that mention the district is slightly over 26 percent. Given a one standard deviation increase in district partisan homogeneity, this percentage decreases to less than 20 percent, on average.

Considering the minority party, we learn that being a member of the minority decreases the average percentage of posts where the member takes a policy position by a factor of 0.58 . Majority party members included in this model $(\mathrm{n}=$ 218) took positions a little over 46 percent of the time, this figure would drop to 27 percent, on average, if they were a member of the minority party. On the other hand, being a member of the minority increases the proportion of posts that mention the district by as factor of 1.67 . The average majority party member mentions the district in a little over 24 percent of posts; our analysis suggests this would grow to over 40 percent, on average, if they are part of the opposition.

If one moves beyond the first two rows, which report findings related to our 
two principal considerations, we see most of the control variable tests do not return coefficients that are statistically significant. The exceptions being, in the position-taking model (Column 2) we find longer serving party leaders and ideologues linked to more position-taking as expected. We also learn that females, on average, were more likely to make position-taking posts. All else being equal, being female increases the average percentage of position-taking posts by a factor of 1.37. In this subsample of legislators, on average, 44 percent of posts made by males were position-taking. Using the factor value, and holding other considerations constant, the percentage of position-taking posts would increase to a little over 60 percent if the member is female.

The findings from our first model runs are telling and confirm our expectations that electoral conditions will sometimes influence the way members present themselves on Facebook. The only primary hypothesis not confirmed is the effect of district partisan homogeneity on position-taking posts. Importantly, this independent variable is significantly correlated with our measure of Ideologue, which is marginally significant. The collinearity in this instance may be compromising our efforts to extract the independent influence of district partisan homogeneity on position-taking posts.

Problems with collinearity aside, we are troubled by these initial model runs for three additional reasons. First, some members' Facebook activity are excluded, namely, those who did not post during the seven observation periods ( $\mathrm{n}$ =37). Second, the proportional measure is compromised by variation in the volume each member posts. For instance, if one member posts twice over the seven observation periods; another member posts 20 times in the seven days; the first member makes one position-taking post; and the second member makes 10 position-taking posts both cases would be scored " 0.50 " on the dependent variable. It is conceivable that both members are equally committed to taking positions on the issues of the day but the larger sample size for the second member gives us more confidence that they are truly willing to do so. The first individual's one position-making post may have been idiosyncratic behavior and our analysis would not pick this up. Third, the testing does not allow us to assess the day of the week or legislative recesses, considerations that theoretically can influence the substance of Facebook posts. To address these concerns we now turn to the analysis that uses each member observation/post as the unit of analysis.

Looking at the results displayed in the second column of Table 2 we learn straightaway that being an ideologue still associate with a greater likelihood of taking policy positions, but this positive test does not prevent the assessment of district partisan homogeneity, one of our principal concerns, from returning a positive and statistically significant relationship with position-taking. Moreover, members of the minority party are less likely, on average, to make position-taking posts collaborating our test from the first set of models. Now, most of the control variables are also performing as hypothesized. Sponsoring more bills increases the probability of position-taking $(p<0.10)$ as does being a longer 
Table 2. Further Exploration of the Substance of Member Facebook Posts: $113^{\text {th }}$ Congress. Logit Regression: Each Member Post is the Unit of Analysis; Robust Standard Errors (s.e.) Clustered by Member.

\begin{tabular}{|c|c|c|c|c|}
\hline \multirow[b]{2}{*}{ Independent Variables } & \multicolumn{2}{|c|}{ Position-Taking Posts } & \multicolumn{2}{|c|}{ District Mention Posts } \\
\hline & Expectation & Coef. (s.e.) & Expectation & Coef. (s.e.) \\
\hline District Partisan Homogeneity & Positive & $0.013(0.007)^{\star}$ & Negative & $-0.029(0.008)^{\star}$ \\
\hline Minority Party Member & Negative & $-0.588(0.189)^{*}$ & Positive & $0.397(0.180)^{*}$ \\
\hline Bills Sponsored (count) & Positive & $0.032(0.019)^{\mathrm{t}}$ & Null & $-0.006(0.023)$ \\
\hline Member Tenure & Negative & $-0.031(0.017)^{\star}$ & Negative & $-0.021(0.011)^{\star}$ \\
\hline Party Leaders & Undefined $^{\mathrm{a}}$ & $-1.09(0.568)$ & Undefined & $-1.09(1.23)$ \\
\hline Tenure x Party Leader & Positive & $0.092(0.022)^{\star}$ & Null & $0.034(0.044)$ \\
\hline Chairs/Ranking Members & Undefined & $-0.535(0.414)$ & Undefined & $-0.980(0.540)$ \\
\hline Tenure $\times$ Chairs/Ranking & Positive & $0.034(0.017)^{*}$ & Negative & $0.043(0.025)^{*}$ \\
\hline Ideologue & Positive & $0.618(0.284)^{*}$ & Null & $-0.376(0.300)$ \\
\hline Female & Null & $0.201(0.137)^{\mathrm{t}}$ & Null & $0.09(0.16)$ \\
\hline Member Age & Null & $0.000(0.000)$ & Null & $-0.013(0.007)^{\star}$ \\
\hline Medium Dist. Income (10,000’s \$) & Positive & $0.008(0.005)^{\mathrm{t}}$ & Negative & $0.004(0.008)$ \\
\hline \% District College Educated & Positive & $-0.000(0.003)$ & Negative & $-0.008(0.005)^{t}$ \\
\hline Legislative Recess ${ }^{\mathrm{b}}$ & Negative & $-0.293(0.103)^{\star}$ & Positive & $0.817(0.127)^{*}$ \\
\hline Constant & \multicolumn{2}{|c|}{$-2.62(0.52)^{*}$} & \multicolumn{2}{|c|}{$-2.24(0.47)^{\star}$} \\
\hline Wald $\mathrm{Chi}^{2}$ & \multicolumn{2}{|c|}{$237.9^{*}$} & \multicolumn{2}{|c|}{$167.4^{*}$} \\
\hline Pseudo $\mathrm{R}^{2}$ & \multicolumn{2}{|c|}{0.09} & \multicolumn{2}{|r|}{0.07} \\
\hline n-observations & \multicolumn{2}{|c|}{4159} & \multicolumn{2}{|r|}{4159} \\
\hline
\end{tabular}

${ }^{\mathrm{t}} p<0.10 ;{ }^{\star} p<0.05$. 'Some expectations are "undefined" because they do not represent real-world conditions. Because of the specified interaction between party leaders and member tenure the coefficient for "Party Leaders" represents the probability of a party leader with no tenure making a position-taking post. Party leaders with no tenure do not exist. ' Dummy variables are employed in both models for each day of the week with Sunday as the reference point. The probability that members will make position-taking and district mention posts is lowest on Sundays. With the exception of Saturday in the position-taking model these are statistically significant findings. The probability of a position-taking post is highest on Wednesdays and the probability of a district mention is highest on Friday.

serving leader or a long serving chair or ranking member. If these leaders are the party agents many believe them to be, this finding is consistent with their contentions.

From the district model (results displayed in the last column of Table 2) we note the inverse relationship expected between district partisan homogeneity and district mentions on Facebook. In other words, a more heterogeneous mix of partisan voting in presidential elections associates with members posting more about their district connections. This suggests, at some level, that closer electoral competition causes a member to perform more as a delegate than a trustee, and at minimum, suggests the member is more consistently reminding others, and themselves, about their district involvement. Minority party members, for their part, are more likely to mention the district, suggesting they may 
be communicating with the public from a more humble posture as they seek to hold their seat and perhaps contribute to their party regaining majority control.

To obtain a better understanding of the behavioral pattern of minority party members versus majority party members, and the role of safe electoral districts, we generate predicted probabilities of position-taking posts according to each member's district partisan homogeneity. Figure 1 demonstrates that at each level of district partisan sameness members of the majority are more likely to take positions than their opponents. When a district is more heterogeneous (homogeneous score equals zero) the probability that a member of the majority will take a position on an issue is about 0.24 . This grows to over 0.35 in the most homogeneous district. Arguably, relative electoral safety allows members to feel more comfortable expressing their views. Minority party members start at a lower probability (about 0.15 ) but this grows to about 0.24 under conditions of the most uniform district. Again, suggesting safer districts lead to more position-taking. But, even in the safest districts, minority party members on average, are less likely than majority party members to make position-taking posts.

As in the previous model, we also calculate predicted probabilities of partisans mentioning the district, based on different values of district partisan homogeneity. As can be seen in Figure 2, members from the most heterogeneous districts (lefthand side of the Figure) tend to mention the district more. In the most homogeneous districts (right-hand side of the Figure), minority and majority party member posts mention the district less than ten percent of the time, on average, all else being equal. Again, however, there is a difference associated with minority party status. In the least homogeneous districts, minority party members associate with about a 23 percent chance of a district post, while majority party members associate with less than a 17 percent chance of mentioning the district. Importantly,

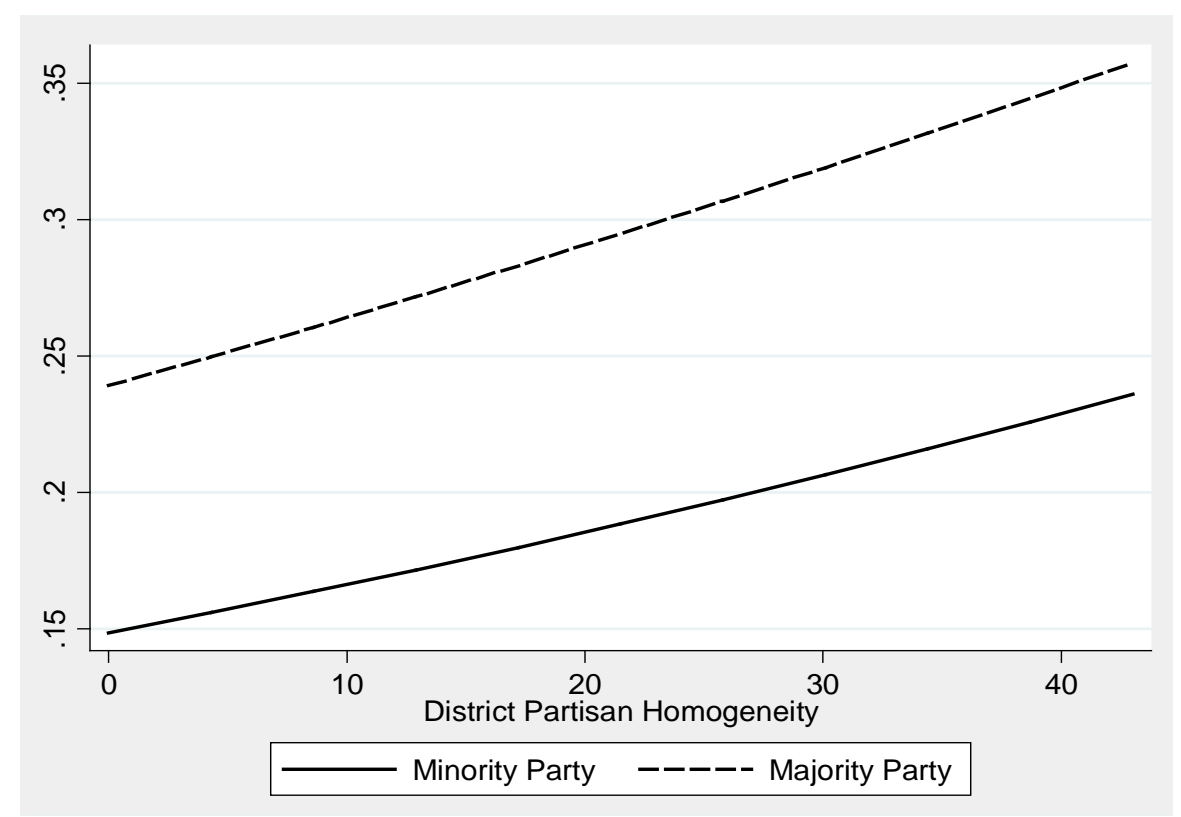

Figure 1. Change in the Predicted Probability that a Party Member will make a Position-Taking Post at Different Levels of District Partisan Homogeneity. 


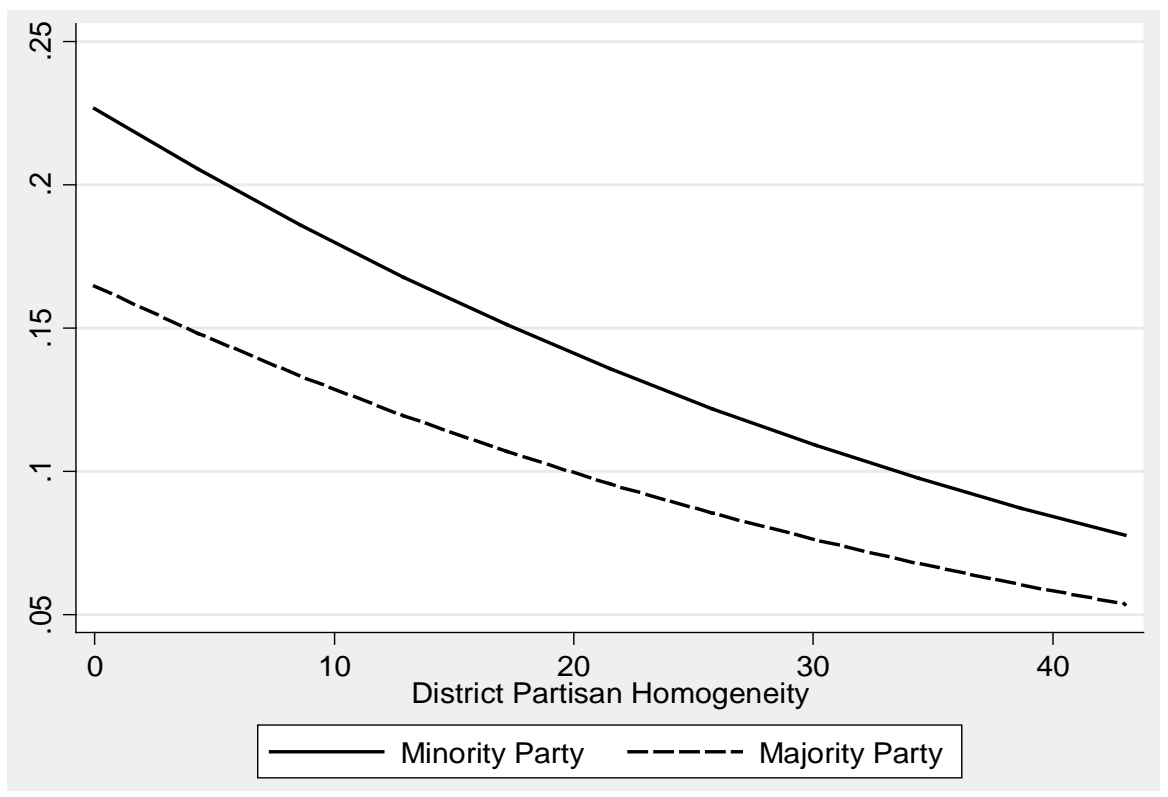

Figure 2. Change in the Predicted Probability that a Party Member will make a District Post at Different Levels of District Partisan Homogeneity.

both groups are more likely to mention the district under conditions of greater electoral vulnerability or more heterogeneous districts.

\section{Discussion}

Previous research suggests the main reason that individuals follow members of Congress on social media and the Internet is to learn their issue positions ([25] [26]). Literature on representation indicates that explaining policy positions to the public is crucially important to the politician/constituent relationship ([3]). Moreover, voters are more likely to hold candidates accountable, at election time, for their stated positions than their actual voting record ([27]). Members of Congress sharing their issue positions and the reasons for their policy preferences with the public, arguably, have direct bearing on the quality of representation, both in terms of ideological congruence and in terms of educating and informing the electorate. ${ }^{12}$ Daniel Lapinski [28] argues the effort, a member of Congress puts into explaining her positions has a significant effect on how well constituents understand and are able to recall those positions. Results from this work suggest that it is members of the majority party and electorally safer members who are more willing to do this.

Additionally, if one values a delegate style of representation wherein legislators concern themselves with the district they represent first; the results of this research have a prescriptive story to tell. More attention to the district will be obtained under conditions of greater partisan heterogeneity, which is analogous to greater electoral competition. We now know that members in the safest districts are less likely to discuss the district. Paying attention to one's district seems

${ }^{12}$ For an important advancement on matching citizen and elite ideologies using Facebook activity see [29]. 
to occur more when the threat of being removed from office is the greatest. Redistricting processes that dilute electoral competition by creating more partisan homogeneous districts can easily cause members to take the district for granted, and only when the threat of inter-party electoral competition grows will this tendency attenuate.

Perhaps, the most normatively appealing finding from this research is that members actively sponsoring legislation associate with more position-taking posts and this is the case after controlling for electoral conditions. This suggests that policy entrepreneurs may be using the new medium as a way to build public support for policy proposals. But, unfortunately, this theoretically attractive use of social media must face the fact that there is considerable variety in the position-taking posts member offices make. Some position-taking posts resembled competent and meaningful policy advocacy, but many others are clearly inflammatory and divisive. Unfortunately, it is not difficult to imagine position-taking posts serving the normatively unappealing role of enflaming the passions of Facebook followers in a manner that might prompt incivility in political discourse. Moreover, if one is afforded the assumption that members representing more partisan homogeneous districts are more extreme in their issue preferences, our findings point to a possible bias in the policy prescriptions being advertised by members of Congress on Facebook. Members emanating from marginal districts might be presumed more moderate and these individuals are less likely to be taking policy positions. The underrepresentation of moderate voices in policy discussions may be prompting a less judicious political dialogue on social media sites.

After completing this work it is not difficult for us to suppose social media communication adding to an already vitriolic and partisan dialogue that defines many political conversations in the $21^{\text {st }}$ century United States. Moreover, it is important to recognize that messages on Facebook, unlike press releases to a local newspaper or a town hall meeting held in the district, have greater potential to be seen by a national audience. More ideologically extreme representatives, from the majority party, who reside in partisan homogeneous districts, are the ones doing more "talking," and it is their positions or views that are being best represented on Facebook. Perhaps this "communication" is tainting national political discourse. Operationally, member communication style on social media may have implications beyond the strategic electoral implications this research set out to uncover.

\section{References}

[1] Grimmer, J. (2013) Representational Style: What Legislators Say and Why It Matters. Cambridge University Press, New York. https://doi.org/10.1017/CBO9781139207782

[2] Grimmer, J., Westwood, S.J. and Messing, S. (2015) The Impression of Influence: Legislator Communication, Representation, and Democratic Accountability. Princeton University Press, Princeton.

[3] Fenno, R.F. (1978) Home Style: House Members in their Home Districts. Longman 
Press, New York.

[4] Glassman, E.M., Straus, J.R. and Shogan, C.J. (2010) Social Networking and Constituent Communications: Member Use of Twitter during a Two-Month Period in the 111th Congress. R41066, Congressional Research Service, Washington DC.

[5] Mayhew, D.R. (2004) Congress: The Electoral Connection. 2nd Edition, Yale University Press, New Haven.

[6] Carson, J.L. and Jenkins, J.A. (2011) Examining the Electoral Connection across Time. Annual Review of Political Science, 14, 25-46. https://doi.org/10.1146/annurev-polisci-030310-221852

[7] Hibbing, J.R. (1991) Congressional Careers: Contours of Life in the U.S. House of Representatives. North Carolina University Press, Chapel Hill.

[8] Jacobson, G.C. (1989) Strategic Politicians and the Dynamics of U.S. House Elections: 1946-86. The American Political Science Review, 83, 773-793.

https://doi.org/10.2307/1962060

[9] Bailey, M. and Brady, D.W. (1998) Heterogeneity and Representation: The Senate and Free Trade. American Journal of Political Science, 42, 524-544. https://doi.org/10.2307/2991769

[10] Harden, J.J. and Carsey, T.M. (2012) Balancing Constituency Representation and Party Responsiveness in the US Senate: The Conditioning Effect of State Ideological Heterogeneity. Public Choice, 150, 137-154. https://doi.org/10.1007/s11127-010-9693-7

[11] Parker, G.R. (1989) Characteristics of Congress: Patterns in Congressional Behavior. Prentice Hall, Englewood Cliffs.

[12] Ashworth, S. (2012) Electoral Accountability: Recent Theoretical and Empirical Work. Annual Review of Political Science, 15, 183-201. https://doi.org/10.1146/annurev-polisci-031710-103823

[13] Glassman, E.M., Straus, J.R. and Shogan, C.J. (2013) Social Networking and Constituent Communications: Member Use of Twitter and Facebook during a TwoMonth Period in the 112th Congress. R43018, Congressional Research Service, Washington DC.

[14] Greenberg, S.R. (2012) Congress + Social Media. Center for Politics and Governance, Austin.

http://www.utexas.edu/lbj/news/2013/congressional-use-social-media-revealed-lbj-s chool-research

[15] Jenkins, J.A., Crespin, M.H. and Carson, J.L. (2005) Parties as Procedural Coalitions in Congress: An Examination of Differing Career Tracks. Legislative Studies Quarterly, 30, 365-389. https://doi.org/10.3162/036298005X201590

[16] Jones, D.R. (2010) Partisan Polarization and Congressional Accountability in House Elections. American Journal of Political Science, 54, 323-337. https://doi.org/10.1111/j.1540-5907.2010.00433.x

[17] Cox, G.W. and McCubbins, M.D. (2007) Legislative Leviathan: Party Government in the House. Cambridge University Press, New York. https://doi.org/10.1017/CBO9780511810060

[18] Rohde, D. (1991) Parties and Leaders in the Postreform House. University of Chicago Press, Chicago. https://doi.org/10.7208/chicago/9780226724058.001.0001

[19] Sinclair, B. (1992) The Emergence of Strong Leadership in the 1980s House of Representatives. The Journal of Politics, 54, 657-684. https://doi.org/10.2307/2132306

[20] Sinclair, B. (1995) Legislators, Leaders, and Lawmaking: The U.S. House of Representatives in the Postreform Era. John Hopkins University Press, Baltimore. 
[21] Sinclair, B. (1999) Transformational Leader or Faithful Agent? Principal-Agent Theory and House Party Leadership. Legislative Studies Quarterly, 24, 421-448. https://doi.org/10.2307/440351

[22] Cover, A.D. (1980) Contacting Congressional Constituents: Some Patterns of Perquisite Use. American Journal of Political Science, 24, 125-135. https://doi.org/10.2307/2110928

[23] Fiorina, M.P., Abrams, S.J. and Pope, J.C. (2006) Culture War? The Myth of a Polarized America. 2nd Edition, Pearson Longman, New York.

[24] Long, J.S. (1997) Regression Models for Categorical and Limited Dependent Variables. Sage Publications, Thousand Oaks.

[25] Andersen, K.N. and Medaglia, R. (2009) The Use of Facebook in National Election Campaigns: Politics as Usual? Lecture Notes in Computer Science, 5694, 101-111. https://doi.org/10.1007/978-3-642-03781-8_10

[26] Hindman, M. (2009) The Myth of Digital Democracy. Princeton University Press, Princeton.

[27] Jones, P.E. (2011) Which Buck Stops Here? Accountability for Policy Positions and Policy Outcomes in Congress. The Journal of Politics, 73, 764-782. https://doi.org/10.1017/S0022381611000442

[28] Lipinski, D. (2001) The Effect of Messages Communicated by Members of Congress: The Impact of Publicizing Votes. Legislative Studies Quarterly, 26, 81-100. https://doi.org/10.2307/440404

[29] Bond, R. and Messing, S. (2015) Quantifying Social Media's Political Space: Estimating Ideology from Revealed Preferences on Facebook. American Political Science Review, 109, 62-78. https://doi.org/10.1017/S0003055414000525

\section{Scientific Research Publishing}

\section{Submit or recommend next manuscript to SCIRP and we will provide best service for you:}

Accepting pre-submission inquiries through Email, Facebook, LinkedIn, Twitter, etc. A wide selection of journals (inclusive of 9 subjects, more than 200 journals)

Providing 24-hour high-quality service

User-friendly online submission system

Fair and swift peer-review system

Efficient typesetting and proofreading procedure

Display of the result of downloads and visits, as well as the number of cited articles

Maximum dissemination of your research work

Submit your manuscript at: http://papersubmission.scirp.org/

Or contact sn@scirp.org 